\title{
Changes of Fructose Concentrations in Seminal Plasma and Glucose and Testosterone Concentrations in Blood Plasma in Rams Over the Course of a Year
}

\author{
Taiki MATSUOKA ${ }^{1)}$, Hiroko IMAI ${ }^{1)}$, Sadaki ASAKUMA ${ }^{2)}$, Hirohide KOHNO ${ }^{3)}$ \\ and Yutaka FUKUI')
}

${ }^{1)}$ Laboratory of Animal Reproduction, Obihiro University of Agriculture and Veterinary Medicine, ${ }^{2)}$ Graduate School of Food Hygiene, Obihiro University of Agriculture and Veterinary Medicine, Obihiro 080-8555 and ${ }^{3)}$ National Livestock Breeding Center, Tokachi

Station, Otofuke 080-0572, Japan

\begin{abstract}
The present study was performed to examine seasonal changes in the fructose concentrations of seminal plasma and glucose and testosterone concentrations of blood plasma over the course of a year (from November 2004 to November 2005) using 5 Suffolk rams. Osmolality of the seminal plasma was also measured. The fructose concentrations in the seminal plasma increased as the breeding season approached, with the maximum in October $(179.8 \mathrm{mg} / \mathrm{dl})$ and the minimum in May $(6.9 \mathrm{mg} / \mathrm{dl})$, although there were no significant differences during the year. Osmolality of the seminal plasma in February $(304 \mathrm{mOsm})$ was significantly $(\mathrm{P}<0.05)$ lower than in January $(325 \mathrm{mOsm})$, July (327 mOsm), and August $(325 \mathrm{mOsm})$. It was also significantly $(\mathrm{P}<0.05)$ lower in November $(308$ mOsm) than in January and August. The blood plasma glucose concentration in October (79.3 mg/dl) was significantly $(\mathrm{P}<0.05)$ higher than in January and February $(43.2$ and $43.7 \mathrm{mg} / \mathrm{dl}$, respectively). The blood plasma testosterone $(\mathrm{T})$ concentrations were significantly $(\mathrm{P}<0.05)$ higher in September $(8.5$ $\mathrm{ng} / \mathrm{ml})$ and October $(10.2 \mathrm{ng} / \mathrm{ml})$ than in other months. The fructose concentrations in the seminal plasma appeared to be related to the glucose and $\mathrm{T}$ concentrations in the blood plasma. These results show that fructose concentrations in the seminal plasma and blood plasma glucose and $\mathrm{T}$ concentrations tended to increase during the breeding season, with the highest concentrations in October.

Key words: Fructose, Glucose, Testosterone, Seminal plasma, Ram semen
\end{abstract}

(J. Reprod. Dev. 52: 805-810, 2006)

$\mathrm{n}$ most domestic animals including sheep, artificial insemination (AI) using frozenthawed semen has been extremely important for improvement of male genetic performance. Semen diluents for freezing of spermatozoa usually contain glucose or fructose in egg yolk- or milkbased diluents. In ejaculated semen, fructose is a major saccharide in seminal plasma in most farm

Accepted for publication: August 18, 2006

Published online: September 21, 2006

Correspondence: Y. Fukui (e-mail: fukui@obihiro.ac.jp) animals including sheep. Fructose in the seminal plasma plays an important role in spermatozoa metabolism, and spermatozoa utilize fructose to produce adenosine triphosphate (ATP) [1-6]. As seasonal breeders, ewes show photoperiodic changes in the hypothalamic area, and this stimulation is key for annual reproductive cycles [7, 8]. On the other hand, rams also show seasonal changes in scrotal circumference, scrotal width, and testosterone concentrations [9-12], and it has been 
reported that fructose concentrations in the seminal plasma change annually with a peak in March (breeding season in New Zealand) in Romney and Merino rams [12]. Fructose is synthesized from blood glucose by the accessory reproductive glands, which are stimulated by testosterone [13]. Therefore, it would be worthwhile to investigate the annual changes of fructose in seminal plasma in relation to the glucose and testosterone concentrations in blood plasma. Information on annual fructose concentrations in the seminal plasma would also contribute to determination of an appropriate concentration of fructose to add into semen diluents. Spermatozoa are sensitive to osmotic changes, and osmolality is an important factor influencing sperm survivability when semen diluents are prepared. However, it is unknown whether osmolality in seminal plasma changes seasonally as in the case of fructose concentrations.

The purposes of the present study were to examine the seasonal changes in the fructose concentration of the seminal plasma and the blood plasma glucose and testosterone concentrations of rams over the course of a year. Osmolality of the seminal plasma was also measured to obtain information in relation to the fructose concentrations.

\section{Materials and Methods}

\section{Semen collection and preparation}

Semen was collected from five mature Suffolk rams (2-5 years old) at the National Livestock Breeding Center, Tokachi Station, Japan $\left(43^{\circ} \mathrm{N}\right.$ and $\left.143^{\circ} \mathrm{E}\right)$. The rams were examined for the mating ability before semen collection. They were kept in a grazing pasture during summer and autumn (May to November) and in a grower barn during winter (December to April). They were fed $3 \mathrm{~kg} /$ day of hay (mainly orchards), supplemented with $300 \mathrm{~g} /$ day of concentrates (13\% crude protein and $76 \%$ total digestible nutrients) and $100 \mathrm{~g} /$ day Lucerne pellets, and provided with free access to fresh water and mineral blocks throughout the study. During the present study, two of the five rams died (one in April and the other in August). The cause of death in April was fighting with four other rams, and the other death in August was due to infection with Haemonchus contortus.

Semen collection was performed from November
2004 to November 2005. Semen was collected using a warmed artificial vagina at 3-week intervals during the year. Ejaculates were immediately evaluated for volume, sperm motility, $\mathrm{pH}$, odor, and color. The semen samples were kept at $0 \mathrm{C}$ until further examinations.

\section{Collection of seminal plasma}

Semen samples were centrifuged at 5,000 rpm for $10 \mathrm{~min}$ at $4 \mathrm{C}$ to remove the supernatant solution. The supernatant solution was centrifuged again at $15,000 \mathrm{rpm}$ for $10 \mathrm{~min}$ at $4 \mathrm{C}$. The supernatant solutions, seminal plasma, were stored $-20 \mathrm{C}$ until assay.

\section{Collection of blood plasma}

Ten $\mathrm{mL}$ blood samples were collected via the jugular vein from the same rams at 3-week intervals for the year. The blood samples were kept at $0 \mathrm{C}$ and were centrifuged at 3,000 rpm for $20 \mathrm{~min}$ at $4 \mathrm{C}$ to take the supernatant solution. The supernatant solutions, blood plasma, were stored at $-20 \mathrm{C}$ until assay.

\section{Assay of fructose}

All chemical reagents employed were of the highest commercially available purity. Chloroform, methanol, and sucrose were purchased from Wako (Osaka, Japan). Glucose and fructose were purchased from Sigma (St. Louis, MO, USA).

Extraction of sugars was performed using the modified method by Urashima et al. [14]. Briefly, seminal plasma samples $(100 \mu \mathrm{l})$ were thawed in $900 \mu \mathrm{L}$ distilled water, and $20 \mu \mathrm{l}$ sucrose solution (100 mg/dl) was extracted with $4 \mathrm{~mL}$ of chloroform/methanol $(2: 1, \mathrm{v} / \mathrm{v})$. After centrifugation at 5,000 rpm for $10 \mathrm{~min}$ at $4 \mathrm{C}$, the upper layer was collected and fully parched by rotary evaporation. The residue was then freezedried. After adding $1 \mathrm{ml}$ distilled water to the freeze-dried sample, the solution was centrifuged at $15,000 \mathrm{rpm}$ for $10 \mathrm{~min}$ at $4 \mathrm{C}$, and the supernatant solution was filtered (Millex-LG $0.20 \mu \mathrm{m}$; Millipore Corporation, Bedford, MA, USA) and kept at -20 C until assay.

The assay of fructose was performed by high performance liquid chromatography (HPLC) using the method of Slimestad and Vagen [15]. Separation was achieved using a TSKgel Amido-80 $(4.6 \mathrm{~mm} \times 250 \mathrm{~mm}$; pore size, $80 \mathrm{~nm}$; particle size, 5 


\section{A) Fructose}

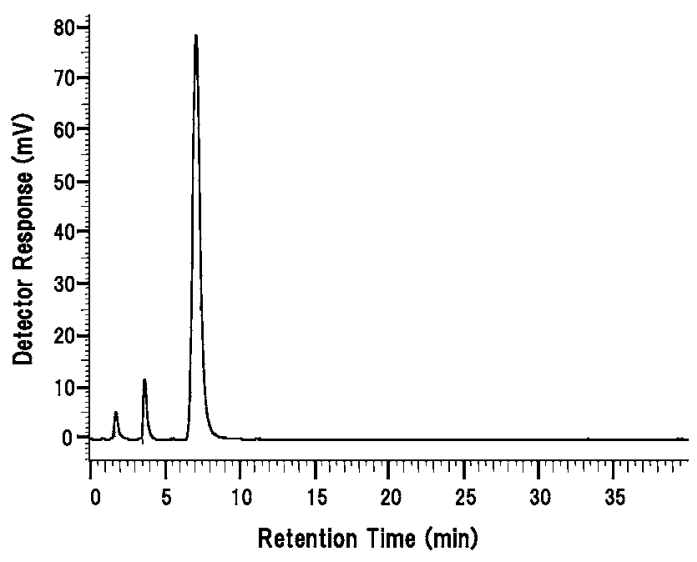

B-1) Seminal plasma (April)

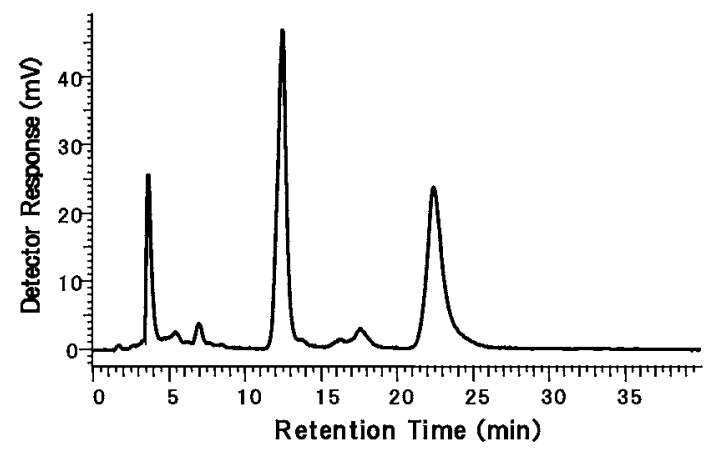

B-2) Seminal plasma (October)

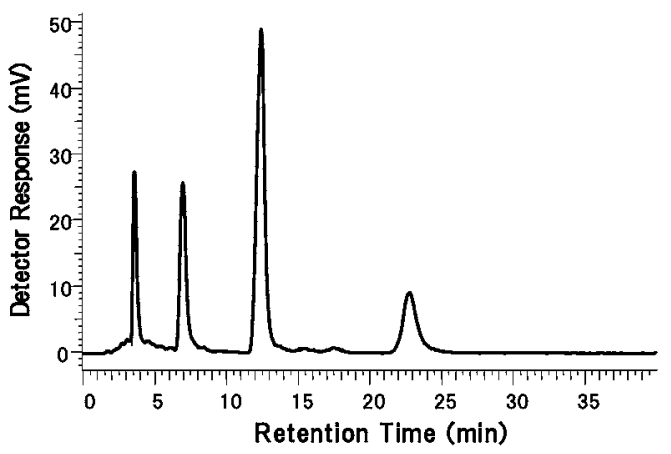

Fig. 1. Chromatographs of fructose and two seminal plasma samples measured by high performance liquid chromatography. A) fructose, B-1) samples in April, and B-2) samples in October. $\mu \mathrm{m})$ normal-phase column (Tosoh Co., Tokyo, Japan). The chromatography was performed at 80 $C$ in an L-7200 column oven (Hitachi, Japan). Detection was performed using a light scattering detector (SEDX 75; Sedere, France) at 45 C. The retention times of fructose and sucrose were confirmed by commercial standards before the sample assay. The fructose concentrations were corrected by the recovery of sucrose in each sample. Representative chromatographs of fructose and two (April and October) seminal plasma samples are shown in Fig. 1.

\section{Assay of glucose}

The glucose concentrations in blood plasma were measured by a colorimetric method using a commercial kit (Glucose Cell Test-Wako; Wako). The intra- and inter- assay coefficients of variation were 3.1 and $3.3 \%$, respectively.

\section{Assay of testosterone}

Based on a previous report [16], the plasma testosterone $(\mathrm{T})$ concentrations were measured directly using a commercial kit (Testosterone EIA Kit, Cayman Chemical Co., Ann Arbor, MI, USA). The intra- and inter-assay coefficients of variation were 4.3 and $7.1 \%$, respectively.

\section{Osmolality in seminal plasma}

The osmolality of seminal plasma was measured by an osmometer (OM801; Vogel Co., Germany). Each sample was measured three times.

\section{Statistical analysis}

The data from measurement of the fructose concentrations and osmolality in the seminal plasma and the glucose and testosterone concentrations in the blood plasma were analyzed by one-way ANOVA. Differences were analyzed by Tukey-Kramer multiple comparison tests using the StatView program (Abacus Concepts, Berkeley, CA, USA). A value of $\mathrm{P}<0.05$ was chosen as an indication of significance.

\section{Results}

\section{Fructose concentrations}

The fructose concentrations in the seminal plasma were not significantly different among the collection months during the year (Fig. 2). 


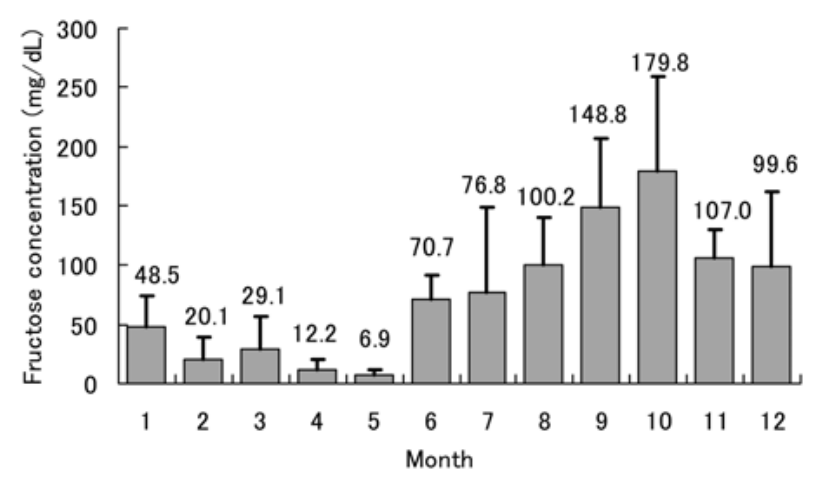

Fig. 2. Seasonal changes in the mean ( \pm SEM) fructose concentrations of the seminal plasma during the year.

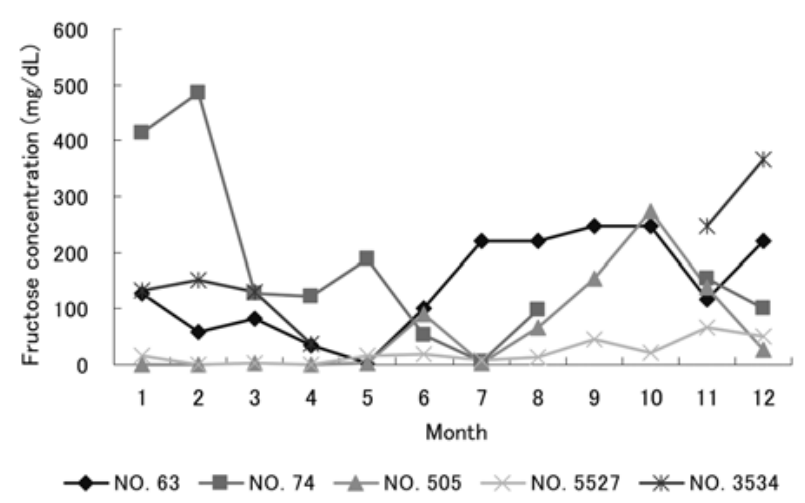

Fig. 3. Seasonal changes in the mean ( \pm SEM) fructose concentration of the seminal plasma of individual rams during a year.

However, the maximum concentration was found in October $(179.8 \mathrm{mg} / \mathrm{d})$, and the minimum concentration was found in May $(6.9 \mathrm{mg} / \mathrm{dl})$. The fructose concentrations in the seminal plasma during the year varied among the individual rams (Fig. 3).

\section{Seminal plasma osmolality}

As shown in Fig. 4, the osmolarity in February (304 mOsm) was significantly $(\mathrm{P}<0.05)$ lower than in January (325 mOsm), July (327 mOsm), and August $(325 \mathrm{mOsm})$. The osmolarity in November (308 mOsm) was also significantly $(\mathrm{P}<0.05)$ lower than in January and August.

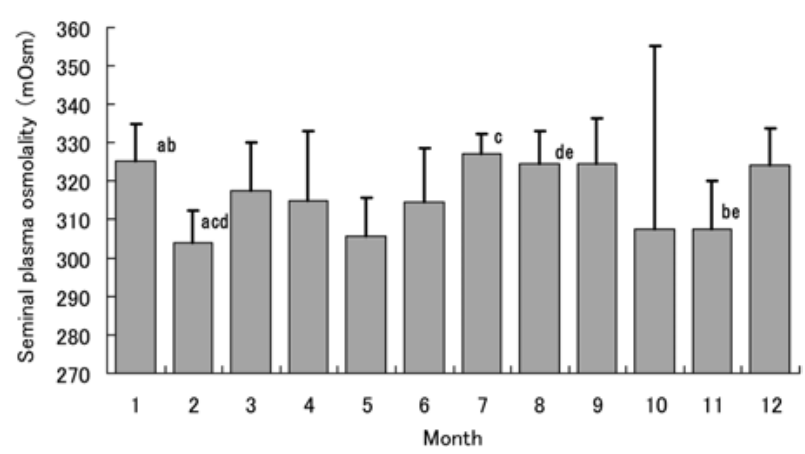

Fig. 4. Seasonal changes in the mean $( \pm$ SEM $)$ seminal plasma osmolality during the year. The same letters (a-e) indicate significant differences $(\mathrm{P}<0.05)$ among the collection months.

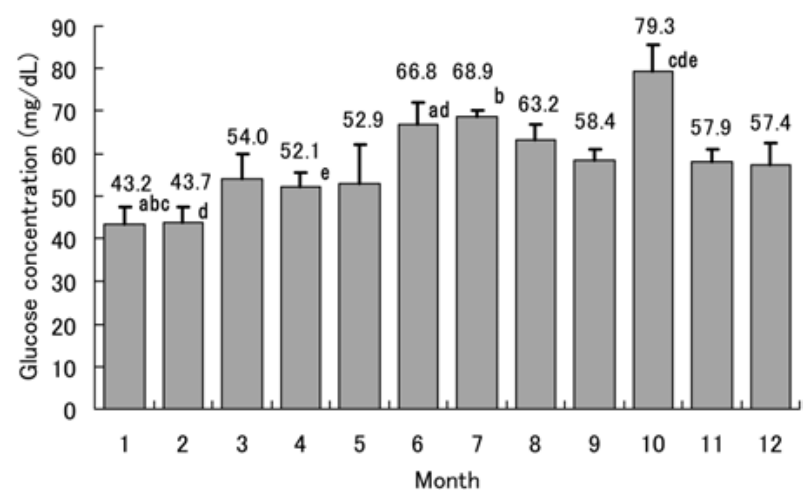

Fig. 5. Seasonal changes in the mean $( \pm$ SEM) blood plasma glucose concentrations during the year. The same letters $(a-e)$ indicate significant differences $(\mathrm{P}<0.05)$ among the collection months.

\section{Glucose concentrations}

As shown in Fig. 5, the concentration in October $(79.3 \mathrm{mg} / \mathrm{dl})$ was significantly $(\mathrm{P}<0.05)$ higher than in January $(43.2 \mathrm{mg} / \mathrm{dl})$, February $(43.7 \mathrm{mg} / \mathrm{dl})$, April $(52.1 \mathrm{mg} / \mathrm{dl})$, and June $(68.9 \mathrm{mg} / \mathrm{dl})$. The glucose concentrations in June and July $(68.9 \mathrm{mg} /$ dl) were significantly $(\mathrm{P}<0.05)$ higher than in January, and the glucose concentration in June was also significantly $(\mathrm{P}<0.05)$ higher than in February.

\section{Testosterone concentrations}

As shown in Fig. 6, the $\mathrm{T}$ concentrations in September $(8.5 \mathrm{ng} / \mathrm{ml})$ and October $(10.2 \mathrm{ng} / \mathrm{ml})$ were significantly $(\mathrm{P}<0.05)$ higher in other months. Also, the $\mathrm{T}$ concentrations in July $(5.2 \mathrm{ng} / \mathrm{ml})$ and August $(6.4 \mathrm{ng} / \mathrm{ml})$ were significantly $(\mathrm{P}<0.05)$ 


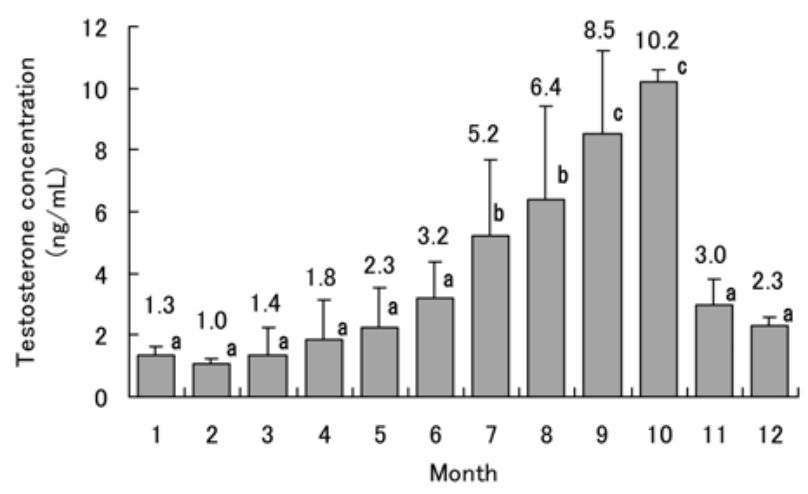

Fig. 6. Seasonal changes in the mean ( \pm SEM) blood plasma testosterone concentrations during the year. Different letters $(\mathrm{a}-\mathrm{c})$ indicate significant differences $(\mathrm{P}<0.05)$ among the collection months.

higher than in November to June (1.0 to $3.2 \mathrm{ng} / \mathrm{ml})$.

\section{Discussion}

Seasonal changes in scrotal circumference, scrotal width, and testosterone concentrations have been observed in rams [9-12]. The rates of pregnant ewes were significantly increased by the conventional (cervical) insemination with the addition of seminal plasma to frozen-thawed semen [1-3]. This has suggested that seminal plasma contains components that protect sperm membranes during cryopreservation and that it plays an important role in survivability of spermatozoa. Fructose is a major component of semen plasma and is secreted by accessory reproductive glands in most animal species. In the present study, the maximal and minimum fructose concentrations in the seminal plasma were observed in October and May, respectively, although there were no significant differences during the year. However, the fructose concentrations in the seminal plasma varied with large variations among the individual rams, and the peak of the fructose concentrations was different among the rams tested. The peak of fructose concentrations in seminal plasma has been reported to be in March (breeding season in New Zealand) in Romney and Merino rams [12]. The differences between the individual ram in the fructose concentrations of the seminal plasma seems to have been caused by the facts that the receptivity to light and hormone action differ between individual rams and breeds (Romney or Merino and Suffolk rams for a previous report [12] and the present study, respectively); however, the fructose concentrations of the seminal plasma in the present study tended to increase as the breeding season approached, which is in agreement with the report of Barrell and Lopwood [12].

In the present study, seminal plasma osmolality did not show any remarkable changes between the breeding and non-breeding seasons, although the fructose concentrations increased during the breeding season. The seminal plasma osmolality in February was significantly lower than in January, July and August. The fructose concentration in October was the highest, but the seminal plasma osmolality was lower in October and November. Although there were individual differences in the seminal plasma fructose concentrations of the five rams tested, individual differences were not observed in the seminal plasma osmolality. Sperm motility in rams generally decreases during the non-breeding period compared with that during the breeding season $[9,10]$. This indicates that the seminal plasma osmolality may not be affected by fructose concentrations.

The blood plasma glucose concentrations were the highest in October and were significantly higher than in January and February. The highest values of glucose in the blood plasma and fructose in the seminal plasma likely corresponded in October. We have considered that the fructose concentration increased due to synthesis of blood glucose. However, the blood plasma glucose concentration did not show any remarkable seasonal changes during the year. The blood glucose concentrations vary with a numbers of factors, including nutritional status such as intake and quality of feeding, energy balance, and body conditions of the individual animals. The low blood glucose concentrations during January and February may have been caused by a severe winter with low temperatures ( -10 to $-20 \mathrm{C})$, and the high blood glucose concentrations during October may have been influenced by stress, such as fighting among the rams grazing in the pasture.

In Merino and Corriedale rams, the maximal and minimal $\mathrm{T}$ concentrations are observed during summer to early autumn and late autumn, respectively [11]. In the present study, the blood plasma $\mathrm{T}$ concentrations increased starting in July, 
with the highest concentrations found in October, and the T levels in September and October were significantly higher than other months. This result indicates that the $\mathrm{T}$ concentration increases as the breeding season approaches and reaches a peak in October, as reported in our previous study [9]. In the present study, the blood plasma $\mathrm{T}$ levels and fructose concentrations in the seminal plasma showed a similar pattern over the course of a year. Although an increase in the blood plasma $\mathrm{T}$ levels as the breeding season approaches, may affect to the seminal plasma fructose concentrations [13], the precise correlation was not clarified in the present study.

In conclusion, the present study showed that the fructose concentrations of the seminal plasma and the blood plasma glucose and $\mathrm{T}$ concentrations tended to increase during the breeding season, with the highest concentrations found in October.

\section{References}

1. Mcphie CA, Evans G, Maxwell WMC. Effect of supplementation of fresh and frozen-thawed semen with seminal plasma on fertility of ewes after cervical and intrauterine insemination. In: 14th Inter Congr Anim Reprod 2000; 2: p78.

2. Gabriel LS, Windsor DP, Eppleston J, Setchell BP, Maxwell WMC. Fertility and its relationship to motility characteristic of spermatozoa insemination with frozen-thawed ram semen. J Androl 1999; 20: 280-288.

3. Maxwell WMC, Evans G, Mortimer ST, Gillan L, Gellatly ES, Mcphie CA. Normal fertility in ewes after cervical insemination with frozen-thawed spermatozoa supplemented with seminal plasma. Reprod Fertil Dev 1999; 11: 123-126.

4. Kamp G, Busselmann G, Lauterwein J. Spermatozoa: models for studying regulatory aspects of energy metabolism. Experientia 1996; 52: 487-494.

5. Rigau T, Farre M, Ballester J, Mogas T, Pena A, Rodriguez-Gill JE. Effects of glucose and fructose on motility patterns of dog spermatozoa from fresh ejaculates. Theriogenology 2001; 56: 801-815.

6. Rigau T, Rivera M, Palomo MJ, Fernandez-Novell JM, Mogas T, Ballester J, Pena A, Otaegui PJ, Guinovart JJ, Rodriguez-Gill JE. Differential effects of glucose and fructose on hexose metabolism in dog spermatozoa. Reproduction 2002; 123: 579-591.

7. Kusakari N. Progress of research on sheep at nonbreeding season. Res Anim Husb 1998; 52: 135-142.

8. Murata A. Research of breeding technology of ewes in non-breeding season. Livestock Tech 2001; 9: 6-9.

9. Fukui Y, Sakamoto K, Ohsaki K, Ono H. Seasonal changes in semen quality and plasma concentration of testosterone in rams. Jpn J Sheep Sci 1991; 28: 5-11.

10. Kusakari N, Ohara M. Seasonal changes of testicular size and semen characteristics in Suffolk rams. Bull Takikawa Anim Husb Exp Stn 1991; 26: 1520.

11. Perez-Clariget $\mathbf{R}$, Forsberg $\mathbf{M}$, Rodriguez-Martinez H. Seasonal variation in live weight, testes size, testosterone, $\mathrm{LH}$ secretion, melatonin and thyroxin in Merino and Corridale rams in a subtropical climate. Acta Vet Scand 1998; 39: 35-47.

12. Barrell GK, Lopwood KR. Seasonality of semen production and plasma lutenizing hormone, testosterone and prolactin levels in Romney, Merino and Polled Dorset rams. Anim Reprod Sci 1979; 1; 213-228.

13. Kumar A, Farooq A. Effect of oxytocin on the concentration of fructose in the accessory glands of mouse. Life Sci 1994; 55: 19-24.

14. Urashima T, Sumiyoshi W, Nakamura T, Arai, I, Saito T, Komatsu T, Tsubota T. Chemical characterization of milk oligosaccharides of the Japanese black bear, Ursus thibetanus japaonicus. Biochim Biophys Acta 1999; 1472: 290-306.

15. Slimestad R, Vagen IM. Thermal stability of glucose and other sugar aldoses in normal phase high performance liquid chromatography. J Chromatography 2006; 1118: 281-284.

16. Watanabe $H$, Mogoe $T$, Asada $M$, Hayashi $K$, Fujise $Y$, Ishikawa $H$, Ohsumi S, Miyamoto A, Fukui Y. Relationship between serum sex hormone concentrations and histology of seminiferous tubules of captured baleen whales in the Western North Pacific during the feeding season. J Reprod Dev 2004; 50: 419-427. 